\title{
Improving CKD Diagnosis and Blood Pressure Control in Primary Care: A Tailored Multifaceted Quality Improvement Programme
}

\author{
John Humphreys ${ }^{a} \quad$ Gill Harvey ${ }^{b, c}$ Janet Hegarty ${ }^{d}$ \\ a NIHR Collaboration for Leadership in Applied Health Research (CLAHRC) Greater Manchester \\ (GM), Salford Royal NHS Foundation Trust, Salford, UK; ${ }^{b}$ Alliance Manchester Business School, \\ University of Manchester, Manchester, UK; ' ${ }^{C}$ Adelaide Nursing School, University of Adelaide, \\ Adelaide, SA, Australia; ${ }^{d}$ Renal Department, Salford Royal NHS Foundation Trust, Salford, UK
}

Keywords

CKD $\cdot$ Diabetes mellitus $\cdot$ Proteinuria $\cdot$ Type 2 diabetes $\cdot$ Blood pressure

\begin{abstract}
Background: Chronic kidney disease (CKD) is a worldwide public health issue. From 2009 to 2014, the National Institute for Health Research Collaboration for Leadership in Applied Health Research and Care Greater Manchester (NIHR CLAHRC GM) in England ran 4 phased, 12-month quality improvement (QI) projects with 49 primary care practices in GM. Two measureable aims were set - halve undiagnosed CKD in participating practices using modelled estimates of prevalence; and optimise blood pressure (BP) control $(<140 / 90 \mathrm{~mm} \mathrm{Hg}$ in CKD patients without proteinuria; $<130 / 80 \mathrm{~mm} \mathrm{Hg}$ in CKD patients with proteinuria) for $75 \%$ of recorded cases of CKD. The 4 projects ran as follows: P1 = Project 1 with 19 practices (September 2009 to September 2010), P2 = Project 2 with 11 practices (March 2011 to March 2012), P3 = Project 3 with 12 practices (September 2012 to October 2013), and P4 = Project 4 with 7 practices (April 2013 to March 2014). Methods: Multifaceted intervention approaches were tailored based on a contextual analysis of practice support needs. Data were collected from practices by facilitators at baseline and again at project close, with self-reported data regularly requested from practices throughout the projects. Results: Halving undiagnosed CKD as per aim was exceeded in 3 of the 4 projects. The optimising BP aim was met in 2 projects. Total CKD cases after the programme increased by 2,347 (27\%) from baseline to 10,968 in a total adult population (aged $\geq 18$ years) of 231,568 . The percentage of patients who managed to appropriate BP targets increased from 34 to 74\% (P1), from 60 to 83\% (P2), from 68 to $71 \%$ (P3), and from 63 to 76\% (P4). In nonproteinuric CKD patients, 88, 90, 89, and 91\%, respec-
\end{abstract}


Humphreys et al.: Improving CKD Diagnosis and BP Control in UK Primary Care Practices

tively, achieved a target BP of $<140 / 90 \mathrm{~mm} \mathrm{Hg}$. In proteinuric CKD patients, 69, 46, 48, and $45 \%$, respectively, achieved a tighter target of $<130 / 80 \mathrm{~mm} \mathrm{Hg}$. Analysis of national data over similar timeframes indicated that practices participating in the programme achieved higher CKD detection rates. Conclusions: Participating practices identified large numbers of "missing" CKD patients with comparator data showing they outperformed non-QI practices locally and nationally over similar timeframes. Improved BP control also occurred through this intervention, but overall achievement of the tighter BP target in proteinuric patients was notably less.

(C) 2017 The Author(s)

Published by S. Karger AG, Basel

\section{Background}

Chronic kidney disease (CKD) is a serious public health issue with a worldwide prevalence of $8-16 \%$ [1], increasing to around $25 \%$ in individuals older than 60 years [2]. International evidence from varied populations suggests that many people with CKD remain undiagnosed, poorly managed, or both [1-4]. Guidelines have been available for over a decade, synthesising evidence on diagnosing and managing CKD [5-7]. Production of clinical guidelines does not guarantee automatic, immediate, or easy translation into clinical practice [8, 9]. Implementation appears to be a complex phenomenon encompassing practitioner beliefs; commitment; knowledge and confidence; the organisation of healthcare processes; systems and delivery; and applying disease-specific guidelines in multimorbid patients. Such complexity has prompted a call for multifaceted, tailored interventions to be applied to address this evidence-into-practice divide $[10,11]$. Questions remain as to how best to tailor multifaceted interventions so they are effectively matched to different contexts [12, 13]. Qualitative research has demonstrated specific challenges around CKD [14]. These include disagreement about whether it is a true disease or represents normal aging; difficulties explaining the condition to patients without frightening them; and scepticism coupled with problems achieving blood pressure (BP) targets. National reporting of CKD stages and management within English National Health Service (NHS) primary care began in 2006 as part of the pay-for-performance (PfP) contract.

This paper describes a phased multifaceted programme of improvement in CKD care in the Greater Manchester (GM) conurbation of the NHS:

- $\quad$ P1 = Project 1 with 19 practices (September 2009 to September 2010)

- $\quad$ P2 = Project 2 with 11 practices (March 2011 to March 2012)

- $\quad$ P3 = Project 3 with 12 practices (September 2012 to October 2013)

- $\quad$ P4 = Project 4 with 7 practices (April 2013 to March 2014)

\section{Study Design}

\section{Setting}

The CKD programme was delivered by the National Institute for Health Research Collaboration for Leadership in Applied Health Research and Care Greater Manchester (NIHR CLAHRC GM). Between 2009 and 2014, it involved 49 primary care practices, split across 4 projects (practice population 231,568 of 2.19 million aged 18+ years). Published data before P1 baseline suggested that the recorded prevalence of CKD patients in GM was considerably lower than prevalence estimates [15]. Further study data [16] were published during P1, which were considered by the Project Advisory Group (the "Expert Faculty") to more accurately represent the prevalence gap - and so initial targets for P1 were adapted in line with 
Humphreys et al.: Improving CKD Diagnosis and BP Control in UK Primary Care Practices

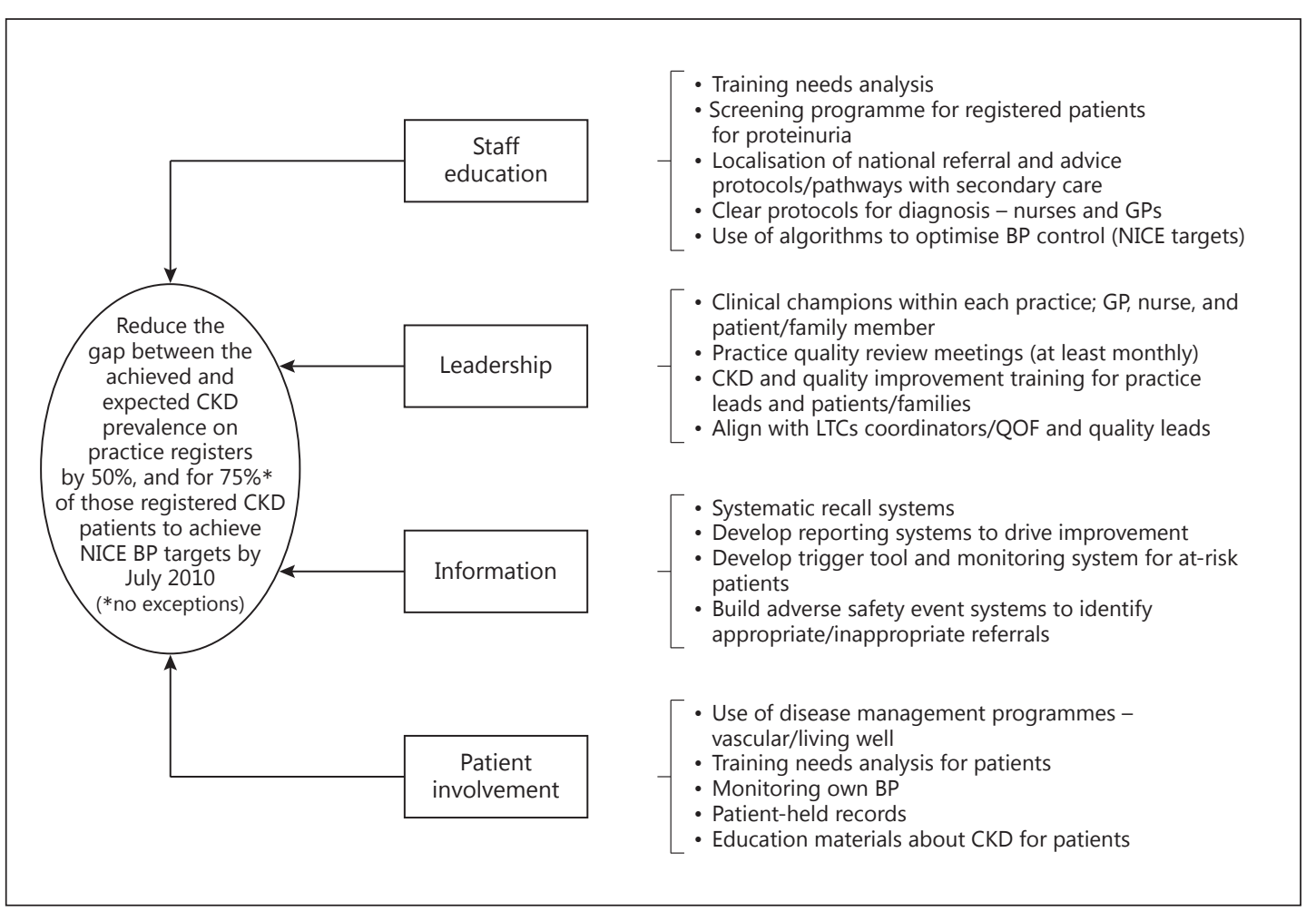

Fig. 1. The NIHR CLAHRC GM CKD collaborative driver diagram.

these findings. The newer data suggested an approximate $2 \%$ prevalence gap, equivalent to around 54,000 undiagnosed cases in GM (the 2008/2009 national recorded prevalence of stages 3-5 CKD was 4.1\%, with an estimated national prevalence of 6\%) [17]. Associations of deprivation with a greater prevalence of CKD may indicate a slightly higher incidence rate in GM compared to the study population that produced the prevalence modelling tool, but there were no data available locally to support or contest this.

The programme was supported in practices by CLAHRC facilitators. Amendments to each project were informed by learning from those that preceded it. In P1, all practices from 4 targeted health economies could apply to participate. Applicants were selected within the available resource to provide a range of practice sizes, demographics, and locations to facilitate learning on implementation. Subsequent projects were largely within single health economies. The programme engaged around $10 \%$ of practices in GM (49/501). They demonstrated considerable heterogeneity (e.g., list numbers 1,585-16,104; adult CKD prevalence at baseline $1.2-7 \%)$.

P1 pre-work included a literature review; stakeholder engagement including a workshop; in-depth local data analyses; and prevalence modelling. This process took around 6 months. The Expert Faculty, comprising patient representatives, primary and secondary care experts, improvement specialists, and local stakeholders, met to agree the framework for change, including setting the aims (Fig. 1). Three educational events were held as per collaborative methodology [18]. Between events, quality improvement (QI) facilitators supported practices to use Plan-Do-Study-Act (PDSA) cycles to test and apply improvements. Each practice was encouraged to form an improvement team (typically a primary care physician, practice nurse, and practice manager). 
Fig. 2. Improvement guide steps for implementing evidence-based care for CKD patients in primary care.

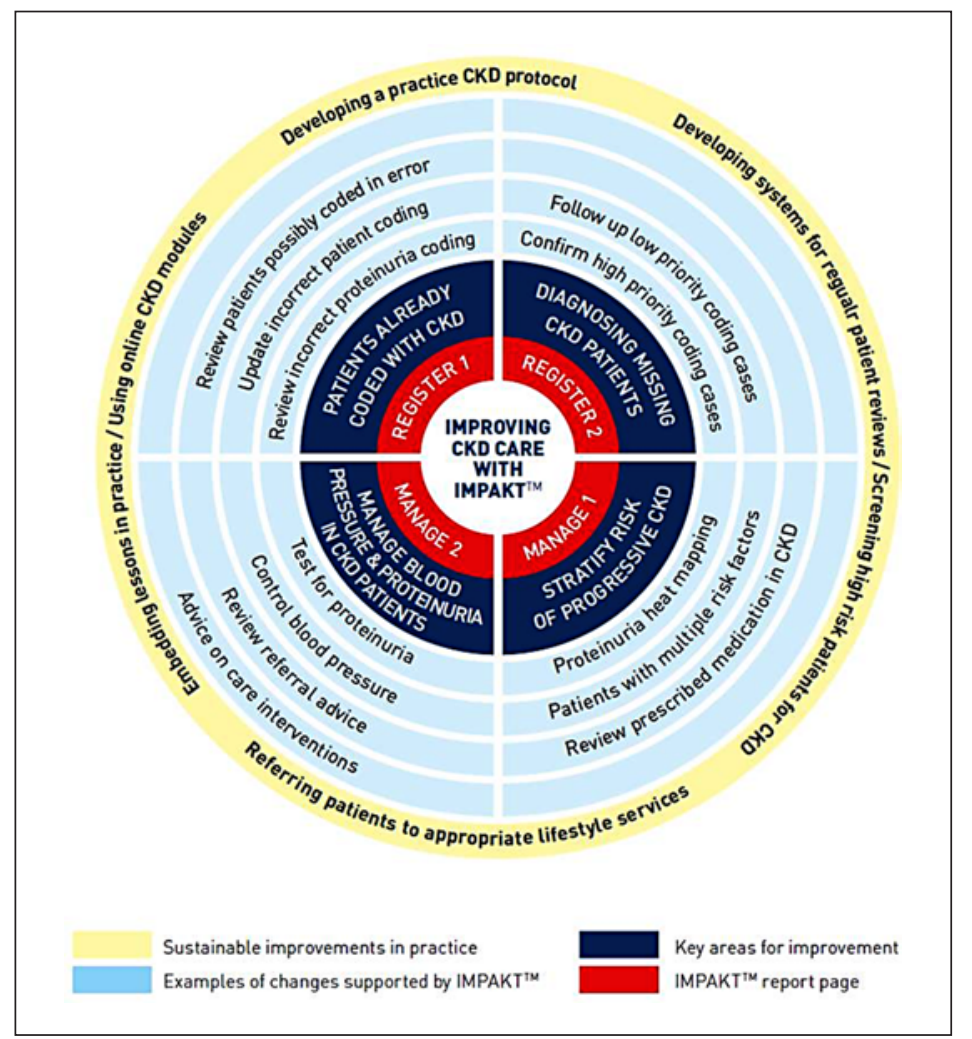

The key learning from P1 was synthesised into a CKD Improvement Guide (Fig. 2) identifying key aspects for improvements in CKD care. This has been previously reported [19], but included (1) validating the existing practice CKD diagnoses; (2) identifying patients who could be immediately diagnosed with CKD and screening patients with eGFR results indicative of CKD; (3) testing for and identifying proteinuria status; (4) ensuring that the patients were aware of their CKD and optimising care regimes primarily through BP control; and (5) introducing methods to sustain practice improvements. Another UK research study simultaneously produced a software programme that could identify and check CKD register codes; identify patients for further testing; detect patients not meeting recommended BP targets; and highlight patients at risk of progressive CKD. This was combined with the Improvement Guide to produce a Computer Decision Support (CDS) tool known as IMPAKT ${ }^{\mathrm{TM}}$ (Improving Patient Care and Awareness of Kidney Disease Progression Together) [20]. Local IT support installed and ran IMPAKT ${ }^{\mathrm{TM}}$ for practices in P2-4. P2 was also run as a traditional QI collaborative (although with some key differences, see Table 1), but P3 and P4 were blended CKD improvement projects, for example, with fewer opportunities for shared learning between practices as the frequency and length of learning sessions were repeatedly reduced. This development of methodology was a result of competing resource demands, financial pressures, leadership attention, and belief that the replication of known/proven improvements (e.g., the CDS) made the achievement of equivalent results "easier."

The CDS tool had unintended benefits for the accuracy of CKD registers by providing clinical data at baseline to support the aforementioned validation stage. This helped facilitators to build the case for change by discussing examples with practices where evidencebased care had not been followed and to structure the education process accordingly. It also meant that, as detection of CKD increased in later stages of the project, facilitators were confident that newly identified patients were valid diagnoses. 
Humphreys et al.: Improving CKD Diagnosis and BP Control in UK Primary Care Practices

Table 1. Differences between the 4 projects of the QI programme

\begin{tabular}{|c|c|c|c|c|}
\hline & Project 1 & Project 2 & Project 3 & Project 4 \\
\hline Timeframe & $2009-2010$ & 2011-2012 & $2012-2013$ & 2013-2014 \\
\hline Practices, $n$ & 19 & 11 & 12 & 7 \\
\hline \multicolumn{5}{|l|}{ CKD prevalence, $\%$} \\
\hline Baseline & 3.6 & 4.6 & 5.2 & 1.5 \\
\hline Estimated & 6.4 & 6.1 & 6.2 & 2.1 \\
\hline \multicolumn{5}{|c|}{ Complex intervention changes throughout programme } \\
\hline $\begin{array}{l}\text { Supporting } \\
\text { technology }\end{array}$ & No CDS tool & $\begin{array}{l}\text { CDS tool used to } \\
\text { support QI framework }\end{array}$ & $\begin{array}{l}\text { Increased use of CDS } \\
\text { tool }\end{array}$ & Increased use of CDS tool \\
\hline $\begin{array}{l}\text { Workshops for } \\
\text { participating } \\
\text { practices }\end{array}$ & $\begin{array}{l}3 \times \text { full-day learning } \\
\text { sessions }\end{array}$ & $\begin{array}{l}2 \times \text { half-day learning } \\
\text { sessions }+5 \text { WebEx } \\
\text { sessions }\end{array}$ & $\begin{array}{l}1 \times 2 \text {-h learning } \\
\text { session }\end{array}$ & $\begin{array}{l}1 \times 1.5 \text {-h learning } \\
\text { session }\end{array}$ \\
\hline $\begin{array}{l}\text { Background of } \\
\text { facilitators }\end{array}$ & $\begin{array}{l}\text { Nonclinical } \\
\text { facilitators }\end{array}$ & $\begin{array}{l}\text { Blend of clinical and } \\
\text { nonclinical facilitators }\end{array}$ & Clinical facilitators & $\begin{array}{l}\text { Blend of clinical and } \\
\text { nonclinical facilitators }\end{array}$ \\
\hline $\begin{array}{l}\text { Experience of } \\
\text { facilitators }\end{array}$ & $\begin{array}{l}\text { Inexperienced } \\
\text { facilitators (new to role } \\
\text { and new project) }\end{array}$ & $\begin{array}{l}\text { Mixed experience level of } \\
\text { facilitators }\end{array}$ & $\begin{array}{l}\text { Mixed experience level } \\
\text { of facilitators }\end{array}$ & $\begin{array}{l}\text { Mixed experience level of } \\
\text { facilitators }\end{array}$ \\
\hline $\begin{array}{l}\text { Experience of } \\
\text { project team in } \\
\text { intervention } \\
\text { sites }\end{array}$ & $\begin{array}{l}\text { No experience of local } \\
\text { implementation } \\
\text { context, politics, and } \\
\text { systems }\end{array}$ & $\begin{array}{l}\text { Some experience of } \\
\text { local implementation } \\
\text { context, politics, and } \\
\text { systems }\end{array}$ & $\begin{array}{l}\text { High experience of local } \\
\text { implementation context, } \\
\text { politics, and systems }\end{array}$ & $\begin{array}{l}\text { No experience of local } \\
\text { implementation } \\
\text { context, politics, and } \\
\text { systems }\end{array}$ \\
\hline $\begin{array}{l}\text { Use of academic } \\
\text { framework to } \\
\text { support delivery }\end{array}$ & $\begin{array}{l}\text { Framework and tools } \\
\text { developed from } \\
\text { generic methodology }\end{array}$ & $\begin{array}{l}\text { Framework and tools } \\
\text { more tailored to formal } \\
\text { project objectives }\end{array}$ & $\begin{array}{l}\text { Framework and tools } \\
\text { highly tailored to } \\
\text { implementation } \\
\text { context }\end{array}$ & $\begin{array}{l}\text { Framework and tools } \\
\text { highly tailored to } \\
\text { implementation } \\
\text { context }\end{array}$ \\
\hline $\begin{array}{l}\text { Reliance on } \\
\text { lessons from } \\
\text { previous projects }\end{array}$ & $\begin{array}{l}\text { Greater testing of } \\
\text { "unknowns" }\end{array}$ & $\begin{array}{l}\text { Developed ideas on } \\
\text { required improvements }\end{array}$ & $\begin{array}{l}\text { Developed ideas on } \\
\text { required improvements }\end{array}$ & $\begin{array}{l}\text { Developed ideas on } \\
\text { required } \\
\text { improvements }\end{array}$ \\
\hline $\begin{array}{l}\text { Financial support } \\
\text { provided to } \\
\text { practices to } \\
\text { "buy-out" time }\end{array}$ & $\begin{array}{l}\text { High financial } \\
\text { support afforded more } \\
\text { time } \\
\text { commitment to test } \\
\text { changes }\end{array}$ & $\begin{array}{l}\text { Small reimbursements } \\
\text { offered; more efficient use } \\
\text { of clinical time on project } \\
\text { required }\end{array}$ & $\begin{array}{l}\text { No reimbursements } \\
\text { offered; highly } \\
\text { efficient use of } \\
\text { clinical time on } \\
\text { project required }\end{array}$ & $\begin{array}{l}\text { No reimbursements } \\
\text { offered; highly } \\
\text { efficient use of clinical } \\
\text { time on project } \\
\text { required }\end{array}$ \\
\hline $\begin{array}{l}\text { Reporting of monthly } \\
\text { data }\end{array}$ & $\begin{array}{l}\text { Data self-reported by } \\
\text { practice teams }\end{array}$ & $\begin{array}{l}\text { Data self-reported by } \\
\text { practice teams }\end{array}$ & $\begin{array}{l}\text { Data extracted by } \\
\text { facilitators }\end{array}$ & $\begin{array}{l}\text { Data extracted by } \\
\text { facilitators }\end{array}$ \\
\hline Project measures & All data NICE aligned & All data NICE aligned & $\begin{array}{l}\text { QOF-aligned baseline } \\
\text { data }\end{array}$ & QOF-aligned baseline data \\
\hline $\begin{array}{l}\text { Evidence for } \\
\text { prevalence } \\
\text { modelling }[15,16]\end{array}$ & $\begin{array}{l}\text { Less developed } \\
\text { evidence for change } \\
\text { (NEOERICA) }\end{array}$ & $\begin{array}{l}\text { More developed } \\
\text { evidence for change } \\
\text { (QICKD) }\end{array}$ & $\begin{array}{l}\text { More developed } \\
\text { evidence for change } \\
\text { (QICKD) }\end{array}$ & $\begin{array}{l}\text { More developed } \\
\text { evidence for change } \\
\text { (QICKD) }\end{array}$ \\
\hline
\end{tabular}

CDS, Computer Decision Support; QOF, Quality and Outcomes Framework.

\section{Data Measures}

Objective 1: Halve the gap between recorded and estimated CKD prevalence. This aim was chosen rather than a fixed \% increase because of the inter-practice variation in baseline prevalence. Patients were regarded as "recorded" if they had been coded with a CKD diagnosis on the practice's clinical system. Estimated prevalence was calculated by mapping practice age/ sex data against a modelling tool developed from previous study findings [16]. 
Humphreys et al.: Improving CKD Diagnosis and BP Control in UK Primary Care Practices

Objective 2: For 75\% of all diagnosed CKD patients to have had their urine tested for proteinuria and their blood pressure managed according to 2 targets $(<140 / 90 \mathrm{~mm} \mathrm{Hg}$ in CKD patients without proteinuria; $<130 / 80 \mathrm{~mm} \mathrm{Hg}$ in CKD patients with proteinuria). Notably, NICE 2008 guidelines recommended the lower BP only in people with diabetes and CKD or with an albumin/creatinine ratio $>70 \mathrm{mg} / \mathrm{mmol}$. The Expert Faculty simplified this to a single programme BP target of $<130 / 80 \mathrm{~mm} \mathrm{Hg}$ in all those coded "with proteinuria."

In P1, 4 of the 19 participating practices, all from 1 health economy, only worked on the first objective due to simultaneous participation in a local improvement initiative targeting hypertensive patients (data shown in Appendix 1).

Monthly data were collected from practices to track progress against the programme measures. Practices constructed and ran searches on their clinical systems to complete a CLAHRC-designed Excel template - standardising the recording of data by practice teams in P1 and P2. In P3 and P4, this template was populated by CLAHRC facilitators during practice visits using PfP data held on clinical systems.

Project close data were self-reported by practices in P1 using the same search template that reported monthly data. In P2-4, facilitators collected this information by manually checking information at each practice. Template-based practice-reported data were satisfactory for the facilitators to use to guide practice improvement, but not considered accurate enough to provide rigorous outcome data. The manual data collection also allowed P3 and P4 to use the same BP targets as P1 and P2 for outcome measures after practices had stopped using the bespoke monthly template; and enabled timeframes to be applied to CKD management measures (Objective 2).

\section{Tailoring Strategies}

The frequency of practice visits by facilitators was titrated to the assessed needs and availability of the practice - and supported by regular telephone/e-mail correspondence and progress reports. Individual outcome measures and run charts were reviewed per practice and results were benchmarked to identify high-/low-achieving practices. A structured assessment framework, based on previous research into the factors that influence the success of improvement initiatives in healthcare was used to inform a tailored practice-level facilitation plan [21,22]. This addressed a range of structural, cultural, political, educational, and technological characteristics that might be acting to facilitate or impede progress.

\section{Analysis}

Outcome data were analysed using run charts. Practices received monthly feedback in comparative dashboards (see Appendix 2). Numbers of patients screened for proteinuria (of those with recorded CKD) were sampled as a process measure.

\section{Results}

Objective 1

In all projects, the recorded CKD prevalence increased (Table 2; Appendix 3). This meant that 3 of 4 projects exceeded their target of diagnosing $50 \%$ of modelled undiagnosed CKD (by $147-161 \%$ of target) and 1 project achieved $92 \%$ of target (P1, in which development work was conducted in IT searches that informed the subsequent phases). In total, practices added 2,347 patients to CKD registers (a 27\% increase from baseline) which equated to an average prevalence change of $+0.9 \%$ (range $0.5-1.4 \%$ ). Due to variation in baseline CKD registers compared to estimates, the individual practice targets for identifying additional patients ranged between -29 and 251. Marked variances in estimated prevalence resulted 
Humphreys et al.: Improving CKD Diagnosis and BP Control in UK Primary Care Practices

Table 2. Change in CKD prevalence in local QI, non-QI, and national comparators using PfP data

$\begin{array}{llllll}\begin{array}{l}\text { Estimated CKD } \\ \text { prevalence }^{1}, \%\end{array} & \begin{array}{l}\text { Target } \\ \text { prevalence }\end{array} & \begin{array}{l}\text { \% of target } \\ \text { prevalence } \\ \text { achieved }\end{array} & \begin{array}{l}\text { Change in CKD } \\ \text { prevalence }(\% \\ \text { of } 18+\text { years } \\ \text { practice list })\end{array} & \begin{array}{l}\text { Absolute } \\ \text { change, } \\ \% \text { points }\end{array} & \begin{array}{l}\text { Relative } \\ \text { increase, }\end{array} \\ & & & \end{array}$

Project 1 (PfP non-QI and national data from March 2009 and March 2011)

Local QI practices $(n=19)$

$\begin{array}{lll}6.4 & 5.1 & 92\end{array}$

Local non-QI practices $(n=208)$

$\mathrm{N} / \mathrm{A}$

$\mathrm{N} / \mathrm{A}$

92
N/A

$3.6 \rightarrow 5.0$

$1.4 \quad 38$

National primary care $(n=8,229)$

N/A

N/A

N/A

\section{$3.7 \rightarrow 4.5$}

0.8

0.2

Project 2 (PfP non-QI and national data from March 2011 and March 2012)

Local QI practices $(n=11)$
Local non-QI practices $(n=105)$
National primary care $(n=8,245)$

$6.1 \quad 5.3$

$\mathrm{N} / \mathrm{A}$

5.3

$\mathrm{N} / \mathrm{A}$

$\mathrm{N} / \mathrm{A}$

154

$\mathrm{N} / \mathrm{A}$

$4.1 \rightarrow 4.3$

22

5

Project 3 (PfP non-QI and national data from March 2012 and March 2014)

N/A

$4.6 \rightarrow 5.8$

$4.4 \rightarrow 4.6$

$4.3 \rightarrow 4.3$

1.2

0.2

0

26

5

0

Local QI practices $(n=12)$

Local non-QI practices $(n=53)$

$6.2 \quad 5.7$

National primary care $(n=8,123)$

$\mathrm{N} / \mathrm{A}$

$\mathrm{N} / \mathrm{A}$

N/A

$\mathrm{N} / \mathrm{A}$

Project 4 (PfP non-QI and national data from March 2013 and March 2014)
Local QI practices $(n=7)$

Local non-QI practices $(n=30)$

National primary care $(n=8,020)$
1.8

$\mathrm{N} / \mathrm{A}$

$\mathrm{N} / \mathrm{A}$

N/A

N/A

161
N/A
N/A

\section{$5.2 \rightarrow 6.0$}

$5.5 \rightarrow 5.3$

$4.3 \rightarrow 4.0$

147
N/A
N/A

$1.5 \rightarrow 2.0$

$2.3 \rightarrow 2.3$

$4.3 \rightarrow 4.0$

(5)

N/A, not applicable. ${ }^{1}$ Based on practice age/sex data taken at baseline. ${ }^{2}$ Objective 1: $50 \%$ improvement in undiagnosed CKD.

from geographical location/demographics of local populations. For example, in P4 the estimated average local prevalence was $2.1 \%$ compared to $4.3 \%$ nationally because the catchment area was heavily populated by students and young professionals. Appendix 4 shows the P2 variation in achievement before and after the intervention to provide a sense of additional work required during the improvement year.

It was beyond the scope of the QI programme to have matched controls. However, we compared our outcomes with simultaneous non-intervention practice PfP data within the same local health economies and used national performance as a further comparator (Table 2). These data demonstrated general increases in prevalence concurrent with P1, most likely driven by the PfP system and further improvements in awareness of CKD through laboratory reporting of CKD stages on routine bloods. The P1 practices still demonstrated a close to 2 -fold increase in CKD prevalence compared to local comparator practices. During P2-4 (2011-2014), there was very little change in prevalence achieved either locally or nationally, but the QI practices did demonstrate a considerable uplift in the number of patients on their CKD registers.

\section{Objective 2}

Meeting this objective required testing all recorded CKD patients for proteinuria to triage them to the appropriate target BP. Proteinuria testing was added into the PfP framework just prior to $\mathrm{P} 1$ ( $n=19$ practices) baseline. Therefore, few CKD patients on practice registers had been tested for proteinuria (35\%). This accordingly meant that they started with a low number of CKD patients achieving the programme targets for BP control (as they could only score "achieving" if a proteinuria check was available and therefore target BP known). The percentage of patients who managed to appropriate BP targets in P1 increased from 34 to $74 \%$. By P2, proteinuria testing had become routine and practices in P2-4 started from much 
Humphreys et al.: Improving CKD Diagnosis and BP Control in UK Primary Care Practices

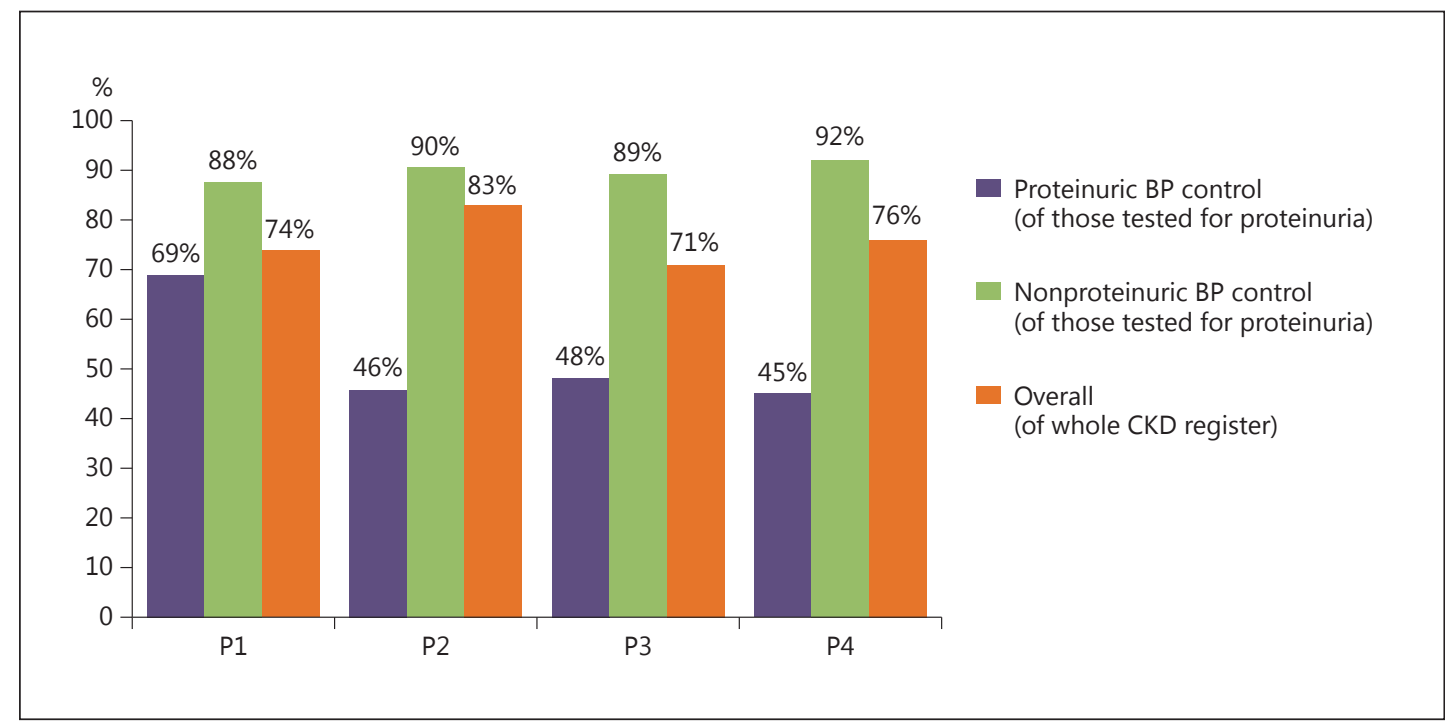

Fig. 3. $\mathrm{BP}$ control in $\mathrm{CKD}$ patients with and without proteinuria at project close for each project.

improved baselines $(92,74$, and $82 \%)$. An average of $9 \%$ of registered CKD patients within the programme had proteinuria (range $4-20 \%$ - based on data collected at the end of each project).

Appendix 1 and Figure 3 show BP achievement throughout the programme. P3 and P4 were delivered within reduced project resources and constrained availability of practice time in the context of systemic NHS reform. One consequence was the aforementioned change in approach to regular practice data collection, reducing the quality and frequency of data available to facilitators. There were no data available on the tighter BP target in proteinurics as this was never included in the PfP framework. In-depth manual data collections were continued at project close by facilitators to accurately record overall practice achievements against objectives. Improvements in overall BP management were recorded throughout the programme. $74 \%$ of patients met the overall BP aim in P1, 83\% in P2, 71\% in P3, and 76\% in $\mathrm{P} 4$. Achievement of target BP was consistently poorer in the subset of proteinuric patients in each project. Figure 3 highlights the discrepant achievement of BP control in those with versus those without proteinuria. Most practices did improve the number of patients at target in the proteinuric group, although considerable variation was noted.

\section{Discussion}

The practices in this initiative demonstrated improvements in the accuracy, size, and management of their CKD registers over 12-month projects. The improvement programme had no formal control arm, but national PfP data enabled us to compare achievements with nonparticipating local practices and national comparators. This showed that intervention practices outperformed both in improving CKD identification throughout the programme.

Topic selection and design of the aims appear to influence whether a QI project will be successful [23]. Identifying a baseline "prevalence gap" was contentious as research evidence on prevalence was limited and the true number of people with CKD in the UK was unknown. This was tackled in 3 ways. Firstly, we involved opinion leaders from both nephrology and 
Humphreys et al.: Improving CKD Diagnosis and BP Control in UK Primary Care Practices

primary care in the Expert Faculty (e.g., the National Clinical Director for Kidney Care). Secondly, the aim to "halve the gap" provided flexibility since the true upper limit was unknown. Thirdly, the evidence base (with attendant limitations) was transparently acknowledged with participating clinicians. Data concurrent with P1 demonstrated general local and national increases in prevalence. The improvement practices still demonstrated an almost 2 -fold increase in CKD prevalence compared to local comparator practices. During P2-4 (2011-2014), there was very little or no change in CKD prevalence achieved either locally or nationally, but the improvement practices recorded a relative increase between 16 and 28\%. These comparator data therefore suggest that this multifaceted programme did result in practices identifying "missing" CKD patients.

BP was used as a proxy measure for improved overall CKD care because of the proven association between improved BP control and reduced risk of vascular events. Practices reported multiple improvements required to achieve this aim (Fig. 2) - including introducing new protocols; winning hearts and minds of colleagues; better data handling and coding; increased and faster use of 24-h ambulatory BP to establish actual BP control; addressing education/training needs; numerous microsystem changes to test (and retest borderline results) for proteinuria across the whole CKD register; overcoming patient anxiety; improving patient information resources; changing or introducing both virtual and face-to-face structured patient reviews that reflected multimorbidity management requirements (addressing holistic needs such as exercise, weight management, salt reduction); prescribing and followup of new vasoactive agents.

Improved achievement of BP control was evident in all projects, but the inter-practice variation of achievement was reduced from P2 onwards. This can be attributed, at least in part, to the elements added between P1 and P2 that improved the efficiency with which the initial stages of improvement could be implemented (leaving more time to focus on the second objective) - in particular the CDS tool.

International data highlight the need for targeted interventions to tackle BP management in CKD. Despite an almost 11\% increase in attainment of BP readings after introduction of PfP in a single health economy in England, almost half of all stage 3-5 CKD patients did not achieve a BP of 145/85 mm Hg in 2010 [24]. A 2013 UK primary care cohort study involving 32 practices found that BP control was suboptimal despite PfP, with $42 \%$ not achieving the NICE BP target, $40 \%$ not achieving the KDIGO BP target, and 64\% not achieving the stricter KDOQI BP target [25]. Low numbers achieving $<140 / 90 \mathrm{~mm} \mathrm{Hg}$ have also been reported in the Kidney Early Evaluation Program (13.6\%) [26], the Turkey-CREDIT Study (13.4\%) [27], and the MERENA Spain cohort (40.8\%) [28].

An average of $9 \%$ of the CKD register in our practices had known significant proteinuria and therefore a lower BP target (range 4-20\%; NB an average of $90 \%$ of the CKD register was tested so this is incomplete as a measure of true proteinuria prevalence). Presumably, the variation in prevalence largely reflected differences in prevalence of type 2 diabetes, for example reflecting local ethnic case mix. We saw wide variation in whether practices achieved the lower BP target in this subset of patients - e.g., the range in P2 was 9-67\% (see Appendix 4). These smaller numbers may well represent the very high-risk patients for progressive CKD. A recent meta-analysis suggests that they are at high risk for cardiovascular events, especially heart failure and cardiovascular death [29].

Despite reports of existing interventions drawing on improvement methods known to effect positive behaviour change in some settings such as academic detailing, care bundles, and rapid cycle improvement - the outcomes reported are variable, underlining the complexity of achieving change which is highly context dependent in multimorbid and elderly patients [12, 30-38]. In 2013, the largest study to date, QICKD, reported its outcomes [36]. This was a cluster randomized controlled trial of 93 primary care practices examining an audit-based education 
Humphreys et al.: Improving CKD Diagnosis and BP Control in UK Primary Care Practices

strategy. They reported a $2.41 \mathrm{~mm} \mathrm{Hg}$ improvement in BP in the audit-based education practices compared to the other arms. This gained an extra 2.8\% of CKD patients achieving the target BP of $<140 / 80 \mathrm{~mm} \mathrm{Hg}$. The authors noted that "it is known that at the population level a reduction of $5 \mathrm{~mm} \mathrm{Hg}$ produces a reduction of about 34\% in stroke and 21\% in IHD." The question remains whether clinical benefits are proportionate to the resource input. We believe one key difference between our multifaceted intervention and that deployed in QICKD was the enabling approach of our facilitation model, which is supported by a growing evidence base [39]. In our setting, the initially resource-intensive model was streamlined throughout P2-4.

Other interventions that hold much promise in CKD include the ones that target deteriorating or at-risk patients; these have included electronic population management via databases with "push" messages sent to primary care physicians or unsolicited risk-driven nephrologist consultations offered [40,41].

We found that QI engagement in this setting is far better received when aligned with PfP targets; tied in with local strategic planning, including financial remuneration to secure protected time of site members to make improvements; a method of sharing evidential clinical data from the practice setting (e.g., CDS) is made available; there is a local clinical champion to provide expert leadership; and the clinical case for change is clearly demonstrable from outcomes elsewhere [42]. Our approach blended clinical guidelines with an evidence-based approach to implementation. We combined elements of structure and direction (e.g., the collaborative model and the CDS tool) with flexibility and responsiveness (e.g., facilitators and practice level assessment and support). This is consistent with recent reports of improvement programmes which highlight the benefits of combining so-called "let-it happen," "help-it happen," and "make-it happen" change strategies [43]. Our findings also demonstrate how difficult it is to achieve consistent levels of improvement across multiple practice settings. This reinforces the fact that variation is inherent in complex interventions $[44,40]$.

\section{Limitations}

As a QI programme and not a controlled trial, there are a number of significant limitations to our work. We did not have a record of actual BP but self-reported achievement against targets during P1 and PfP data extracted by the facilitators during P3 and P4. The actual change in mm $\mathrm{Hg}$ is unknown. In the absence of controls, we do not know how practices in the programme performed in terms of BP management compared to non-intervention practices. Finally, it was beyond the scope of our work to conduct an in-depth measurement of how any improvements were sustained in practices medium- to long-term after the intervention - and how resilient improvements were in the face of competing clinical priorities and service pressures.

\section{Conclusions}

This complex intervention demonstrated successes in increased identification and management of patients with CKD. This has the potential to reduce the longer-term consequences of undiagnosed or suboptimally managed CKD for the healthcare system.

\section{Statement of Ethics}

Ethical approval was not needed for the programme as it was classified as service improvement under the NHS research governance procedures. 


\section{Disclosure Statement}

The authors confirm that they have no financial or other conflicts of interest in relation to the contents of this paper.

\section{Appendix 1}

Aggregate QI programme results over 4 projects.

\begin{tabular}{|c|c|c|c|c|}
\hline & Project No. & & & \\
\hline & $1^{\mathrm{a}, \mathrm{b}}$ & 2 & 3 & 4 \\
\hline Practices & 19 & 11 & 12 & 7 \\
\hline CKD patients & & & & \\
\hline Baseline & 4,185 & 2,055 & 1,871 & 665 \\
\hline End & 5,509 & 2,594 & 2,167 & 853 \\
\hline Achieving "CKD, no proteinuria" & $1,053(98)$ & 1,086 (68) Achieving & $1,312(68)$ & $458(63)$ \\
\hline BP target Pre (140/90 mm Hg) & & QOF CKD BP target of & & \\
\hline (of those coded without & & $(140 / 85 \mathrm{~mm} \mathrm{Hg})-$ all CKD & & \\
\hline 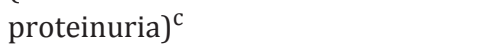 & & $P r e^{\mathrm{c}}$ & & \\
\hline Achieving "CKD + proteinuria" & $182(60)$ & $48(32)$ & $\mathrm{N} / \mathrm{A}$ & $\mathrm{N} / \mathrm{A}$ \\
\hline BP target Pre (130/80 mm Hg) & & & & \\
\hline (of those coded with proteinuria) $^{c}$ & & & & \\
\hline Achieving "CKD, no proteinuria" & $2,798(88)$ & $2,074(90)$ & $1,638(89)$ & $593(92)$ \\
\hline BP target Post (140/90 mm Hg) & & & & \\
\hline $\begin{array}{l}\text { (of those coded without } \\
\text { proteinuria) }\end{array}$ & & & & \\
\hline Achieving "CKD + proteinuria" & $253(69)$ & $82(46)$ & $159(48)$ & $59(45)$ \\
\hline BP target Post (130/80 mm Hg) & & & & \\
\hline (of those coded with proteinuria) & & & & \\
\hline $\mathrm{BP}$ overall at target & $3,051(74)$ & $2,156(83)$ & $1,797(71)$ & $652(76)$ \\
\hline (no exception reporting) & & & & \\
\hline
\end{tabular}

Values are shown as numbers, with percentages in parentheses. QOF, Quality and Outcomes Framework; $\mathrm{N} / \mathrm{A}$, not applicable. ${ }^{\mathrm{a}} 4 / 19$ practices in this project did not work towards objective 2 due to their pre-existing participation in a local improvement initiative that included BP; hence the lower number of patients in the achievement of BP columns. ${ }^{b}$ In Project 1, practices self-reported their baseline, monthly, and outcome data. The figures used here are as reported by practices, as no method of checking the data for accuracy had been built into the first project. Subsequent projects used manual data collection by CLAHRC facilitators to measure outcomes. ${ }^{c}$ Baseline figures for the programme objective 2 measure (BP) were taken by facilitators from practice QOF data in which no subset of those with proteinuria is recorded. 
Humphreys et al.: Improving CKD Diagnosis and BP Control in UK Primary Care Practices

\section{Appendix 2}

Example of a practice level report given in a dashboard comparing participating practices and electronic/paper report formats.

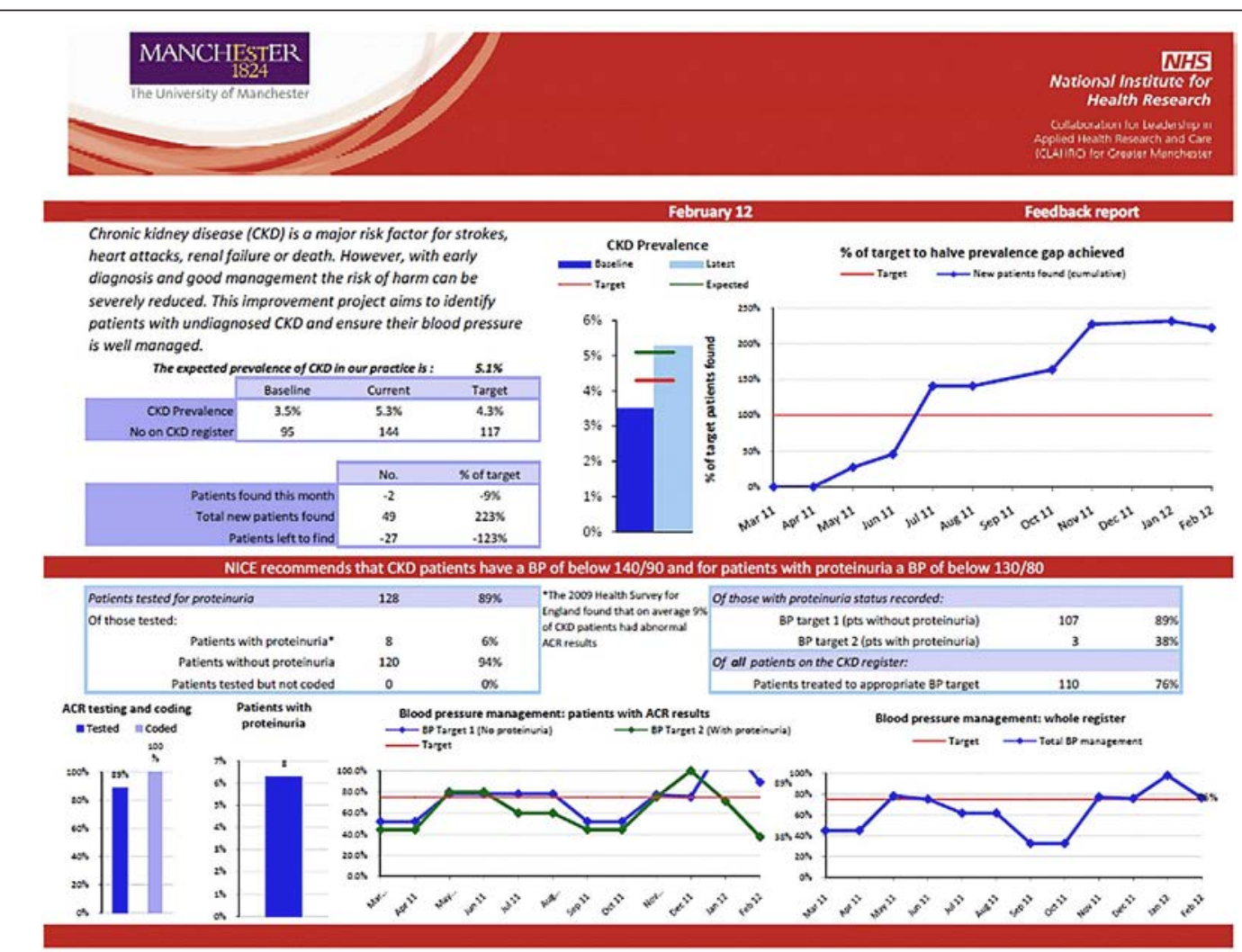

The NHR CUARC for Greater Manchester is a collaboration of Greater Manchester NHS Trusts and the University of Manchester and is part of the National Institute of Health Research w: http://clahre-gm.nihr.acuk e: clahrcesstt.nhs.uk

\section{Appendix 3}

Objective 1 CKD prevalence - overall percentage achievement of patients found to reach target in $\mathrm{P} 1-4$.

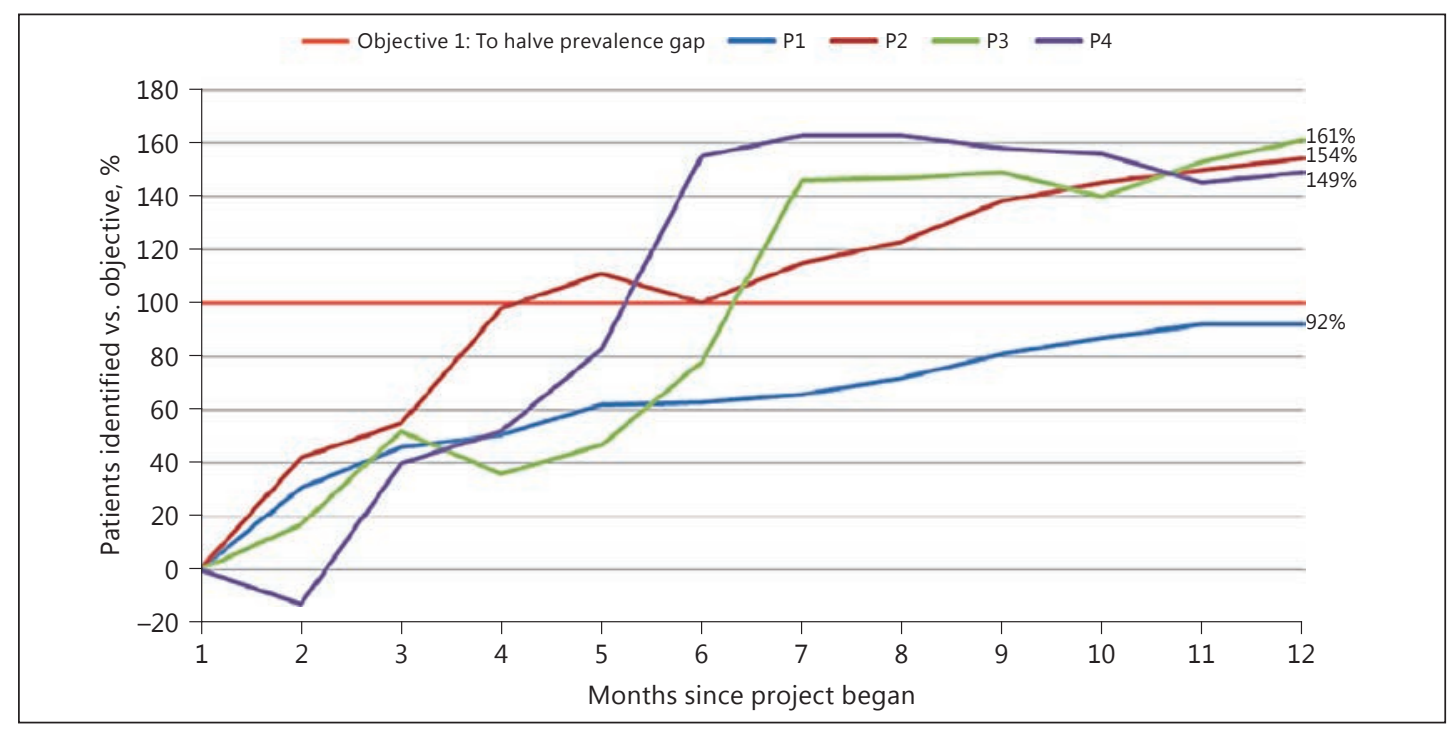


nephron

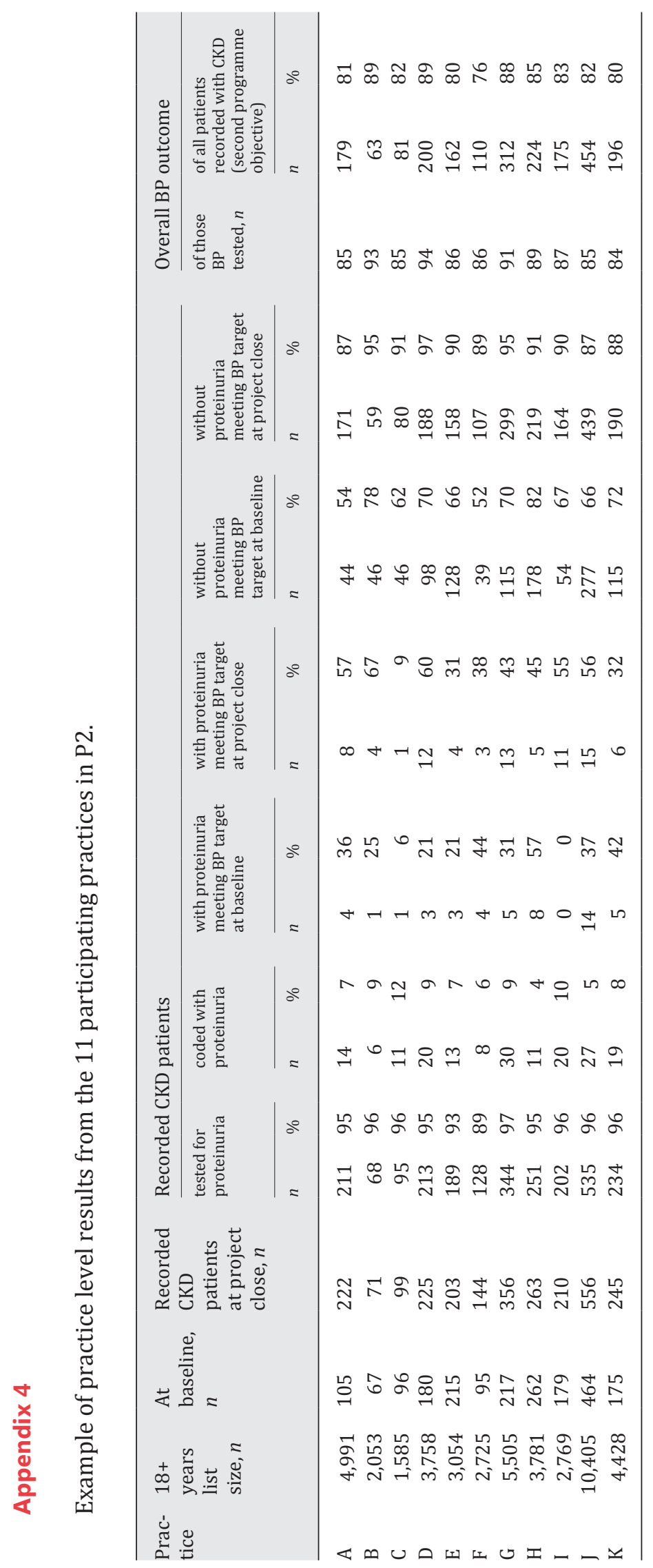

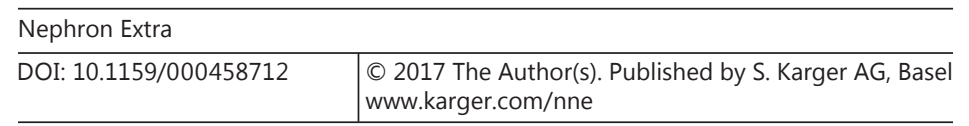

Humphreys et al.: Improving CKD Diagnosis and BP Control in UK Primary Care Practices

www.karger.com/nne

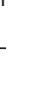

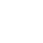


Humphreys et al.: Improving CKD Diagnosis and BP Control in UK Primary Care Practices

\section{References}

1 Jha V, Garcia-Garcia G, Iseki K, Li Z, Naicker S, Plattner B, Saran R, Wang AYM, Yang CW: Chronic kidney disease: global dimension and perspectives. Lancet 2013;382:260-272.

-2 Coresh J, Selvin E, Stevens LA, Manzi J, Kusek JW, Eggers P, Van Lente F, Levey AS: Prevalence of chronic kidney disease in the United States. JAMA 2007;298:2038-2047.

-3 Collins AJ, Foley RN, Chavers B, et al: MD US Renal Data System 2013 Annual Data Report. Am J Kidney Dis 2014;63(1 suppl):A7.

4 Allen AS, Forman JP, Orav EJ, Bates DW, Denker BM, Sequist TD: Primary care management of chronic kidney disease. J Intern Med 2011;26:386-392.

$\checkmark 5$ Levey AS, Coresh J, Balk E, Kausz AT, Levin A, Steffes MW, Hogg RJ, Perrone RD, Lau J, Eknoyan G: National Kidney Foundation practice guidelines for chronic kidney disease: evaluation, classification, and stratification. Ann Intern Med 2003;139:137-147.

6 National Institute for Clinical Excellence (NICE): Chronic Kidney Disease: Early Identification and Management of Chronic Kidney Disease in Adults in Primary and Secondary Care. London, NICE, 2008.

$\checkmark 7$ National Kidney Foundation: K/DOQI Clinical Practice Guidelines for Chronic Kidney Disease: evaluation, classification and stratification. Am J Kidney Dis 2002;39(suppl 1):S17-S31.

-8 Grol R, Grimshaw J: From best evidence to best practice: effective implementation of change in patients' care. Lancet 2003;362:1225-1230.

9 Grimshaw J, Eccles M, Tetroe J: Implementing clinical guidelines: current evidence and future implications. J Contin Educ Health Prof 2004;24(suppl 1):S31-S37.

$\checkmark 10$ Bero LA, Grilli R, Grimshaw JM, Harvey E, Oxman AD, Thomson MA: Closing the gap between research and practice: an overview of systematic reviews of interventions to promote the implementation of research findings. BMJ 1998;317:465-468.

-11 Lemelin J, Hogg W, Baskerville N: Evidence to action: a tailored multifaceted approach to changing family physician practice patterns and improving preventive care. Can Med Assoc J 2001;164:757-763.

12 Matchar DB, Patwardhan MB, Samsa GP, Haley WE: Facilitated process improvement: an approach to the seamless linkage between evidence and practice in CKD. Am J Kidney Dis 2006;47:528-538.

13 Harvey G, Fitzgerald L, Fielden S, McBride A, Waterman H, Bamford D, Kislov R, Boaden R: The NIHR Collaboration for Leadership in Applied Health Research and Care (CLAHRC) for Greater Manchester: combining empirical, theoretical and experiential evidence to design and evaluate a large-scale implementation strategy. Implement Sci 2011;6:96.

14 Crinson I, Gallagher H, Thomas N, de Lusignan S: How ready is general practice to improve quality in chronic kidney disease? A diagnostic analysis. Br J Gen Pract 2010;60:403-409.

$\checkmark 15$ Stevens PE, O’Donoghue D, de Lusignan S, et al: Chronic kidney disease management in the United Kingdom: NEOERICA project results. Kidney Int 2007;72:92-99.

16 de Lusignan S, Tomson C, Harris K, van Vlymen J, Gallagher H: Creatinine fluctuation has a greater effect than the formula to estimate glomerular filtration rate on the prevalence of chronic kidney disease. Nephron Clin Pract 2011;117:c213-c224.

17 Health and Social Care Information Centre. http://qof.hscic.gov.uk/index.asp (accessed July 28, 2014).

18 Institute for Healthcare Improvement: The breakthrough series: IHI's collaborative model for achieving breakthrough improvement. (IHI Innovation Series white paper). Boston, Institute for Healthcare Improvement, 2003.

19 IMPAKT $^{\text {TM }}$. A guide to using IMPAKT ${ }^{\mathrm{TM}}$ to improve diagnosis and care for people with chronic kidney disease. University Hospitals of Leicester NHS Trust, 2013. http://clahrc-gm.nihr.ac.uk/cms/wp-content/uploads/ IMPAKT-CKD-Improvement-Guide.pdf (accessed June 16, 2014).

20 www.impakt.org.uk (accessed January 12, 2016).

21 Bate P, Robert G, Fulop N, Ovretveit J, Dixon-Woods M: Perspectives on Context. A Selection of Essays Considering the Role of Context in Successful Quality Improvement. London, Health Foundation, 2014.

22 Bate P, Mendel P, Robert G: Organising for Quality: The Improvement Journeys of Leading Hospitals in Europe and the United States. Abingdon, Radcliffe, 2008.

23 de Silva D: Improvement Collaboratives in Health Care: Evidence Scan. London, Health Foundation, 2014.

24 Karunaratne K, Stevens P, Irving J, Hobbs H, Kilbride H, Kingston R, Farmer C: The impact of pay for performance on the control of blood pressure in people with chronic kidney disease stage 3-5. Nephrol Dial Transplant 2013;28:2107-2116.

25 Fraser S, Roderick P, Mcintyre N, Harris S, Mcintyre C, Fluck R, Taal MW: Suboptimal blood pressure control in chronic kidney disease stage 3:baseline data from a cohort study in primary care. BMC Fam Pract 2013;14:88.

26 Sarafidis PA, Li S, Chen S-C, Collins AJ, Brown WW, Klag MJ, Bakris GL: Hypertension awareness, treatment, and control in chronic kidney disease. Am J Med 2008;121:332-340.

27 Altun B, Süleymanlar G, Utaş C, Arınsoy T, Ateş K, Ecder T, Camsarı T, Serdengeçti K: Prevalence, awareness, treatment and control of hypertension in adults with chronic kidney disease in Turkey: results from the CREDIT study. Kidney Blood Press Res 2012;36:36-46.

28 Martínez-Castelao A, Górriz JL, Portolés JM, De Alvaro F, Cases A, Luño J, Navarro-González JF, Montes R, De la Cruz-Troca JJ, Natarajan A, Batlle D: Baseline characteristics of patients with chronic kidney disease stage 3 and stage 4 in Spain: the MERENA observational cohort study. BMC Nephrol 2011;12:53. 
29 Matsushita K, Coresh J, Sang Y, Chalmers J, Fox C, Guallar E, Jafar T, Jassal SK, Landman GW, Muntner P, Roderick P, Sairenchi T, Schöttker B, Shankar A, Shlipak M, Tonelli M, Townend J, van Zuilen A, Yamagishi K, Yamashita K, Gansevoort R, Sarnak M, Warnock DG, Woodward M, Ärnlöv J: Estimated glomerular filtration rate and albuminuria for prediction of cardiovascular outcomes: a collaborative meta-analysis of individual participant data. Lancet Diabetes Endocrinol 2015;3:514-525.

-30 Fox CH, Brooks A, Zayas LE, McClellan W, Murray B: Primary care physicians' knowledge and practice patterns in the treatment of chronic kidney disease: an Upstate New York Practice-based Research Network (UNYNET) Study. J Am Board Fam Pract 2006;19:54-61.

-31 Gallagher H, de Lusignan S, Harris K, Cates C: Quality-improvement strategies for the management of hypertension in chronic kidney disease in primary care: a systematic review. Br J Gen Pract 2010;60:e258-e265.

-32 Abdel-Kader K, Fischer GS, Li J, Moore CG, Hess R, Unruh ML: Automated clinical reminders for primary care providers in the care of CKD: a small cluster-randomized controlled trial. Am J Kidney Dis 2011;58:894-902.

-33 Bayliss EA, Bhardwaja B, Ross C, Beck A, Lanese DM: Multidisciplinary team care may slow the rate of decline in renal function. Clin J Am Soc Nephrol 2011;6:704-710.

34 Drawz P, Miller RT, Singh S, Watts B, Kern E: Impact of a chronic kidney disease registry and provider education on guideline adherence - a cluster randomized controlled trial. BMC Med Inform Decis Mak 2012;12:62.

35 Thomas N, Loud F: Managing chronic kidney disease in primary care: a quality improvement study. RSAJ 2012;8:152-157.

-36 de Lusignan S, Gallagher H, Jones S, Chan T, van Vlymen J, Tahir A, Thomas N, Jain N, Dmitrieva O, Rafi I, McGovern A, Harris K: Audit-based education lowers systolic blood pressure in chronic kidney disease: the Quality Improvement in CKD (QICKD) trial results. Kidney Int 2013;84:609-620.

-37 Fox C, Vest B, Kahn L, Dickinson L, Fang H, Pace W, Kimminau K, Vassalotti J, Loskutova N, Peterson K: Improving evidence-based primary care for chronic kidney disease: study protocol for a cluster randomized control trial for translating evidence into practice (TRANSLATE CKD). Implement Sci 2013;8:88.

-38 Mendu ML, Schneider LI, Aizer AA, Singh K, Leaf DE, Lee TH, Waikar SS: Implementation of a CKD checklist for primary care providers. Clin J Am Soc Nephrol 2014:9:1526-1535.

-39 Baskerville NB, Liddy C, Hogg W: Systematic review and meta-analysis of practice facilitation within primary care settings. Ann Fam Med 2012;10:63-74.

40 Kennedy DM, Chatha K, Rayner HC: Laboratory database population surveillance to improve detection of progressive chronic kidney disease. J Ren Care 2013;39(suppl 2):23-29.

41 Lee BJ, Forbes K: The role of specialists in managing the health of populations with chronic illness: the example of chronic kidney disease. BMJ 2009;15:27:38.

42 Kislov R, Humphreys J, Howard S, Soiland-Reyes C, Mellor P, Born A, Wood S, Boaden R: Current primary care priorities for kidney health in Greater Manchester: a CLAHRC GM report on the findings from a consultation exercise to understand primary care priorities around kidney health across Greater Manchester. Salford Royal NHS Foundation Trust, 2015. http://clahrc-gm.nihr.ac.uk/our-work/primary-care/kidney-health/ ahsn-kidney-health/4/.

43 Etheridge F, Couturier Y, Denis J-L, Tremblay L, Tannenbaum C: Explaining the success or failure of quality improvement initiatives in long-term care organizations from a dynamic perspective. J Appl Gerontol 2014;33: 672-689.

44 Schouten LMT, Hulscher MEJL, van Everdingen JJE, Huijsman R, Grol RPTM: Evidence for the impact of quality improvement collaboratives: systematic review. BMJ 2008;336:1491-1494. 